\title{
Fastlegeordningen trenger flere leger
}

\author{
Fastlegeordningen har vært en suksess sett fra pasientenes, allmennlegenes og myndighetenes side. Helse- \\ og omsorgsdepartementets forslag til ny fastlegeforskrift bygger i liten grad på faglige anbefalinger og vil \\ føre til flere oppgaver og mer byråkrati. Det er åpenbart at primærhelsetjenesten vil trenge flere allmenn- \\ leger om intensjonene i den nye forskriften skal bli realisert.
}

\author{
Stian Langeland Wesnes \\ stian.langeland@isf.uib.no \\ Forskningsgruppe for allmennmedisin \\ Institutt for samfunnsmedisinske fag \\ Universitetet i Bergen \\ og \\ Krambua legesenter \\ Bergen
}

Espen Saxhaug Kristoffersen

Avdeling for allmennmedisin

Institutt for helse og samfunn

Universitetet i Oslo

Robert A. Burman

Nasjonalt kompetansesenter for legevaktsmedisin Uni helse

Bergen

Nylig kom Helse- og omsorgsdepartementet med forslag til ny fastlegeforskrift (1). En allmennlege har allerede mange arbeidsoppgaver. I tillegg til ordinære konsultasjoner kommer legevakt, møter med samarbeidspartnere, drift av legekontor, personalmøter, studentveiledning, vedlikehold av stadig mer komplekse IKT-løsninger og selvsagt kurs og faglig fordyping, i tillegg til sentrale pålegg om systematisk pasientsikkerhetsog kvalitetsforbedringsarbeid.

Arbeidsmengden til fastlegene har økt betydelig de senere årene gjennom økte krav fra ulike aktører. Én av fire fastleger i Norge opplevde uakseptabelt arbeidspress i 2008 (2). I tillegg bør fastleger i større grad delta i legevaktsarbeid (3).

Flere pasienter med kroniske sykdommer, reduserte intervensjonsgrenser, redusert egenomsorgsevne og en betydelig eldrebølge er noen av momentene som fører til økte konsultasjonsrater og behov for flere allmennleger. Å følge nasjonale retningslinjer for ti vanlige kroniske sykdommer i en amerikansk legepraksis på 1250 pasienter krever 414 klokketimer i året ved stabil tilstand. Tar vi hensyn til oppsporing, utredning og oppfølging i ustabile faser øker kravet til 1242 timer i året (4).

Allmennmedisin har en rekke rekrutteringsmessige utfordringer. Spesialiteten har lav status (5). Den har den svakeste akade- miske forankringen blant alle spesialiteter, er den eneste spesialiteten som krever betydelig egenkapital ved oppstart, og er samtidig en spesialitet med dårlige sosiale og pensjonsmessige rettigheter.

\section{Mangel på allmennleger før forskriften}

Ingen annen legespesialitet i Norge har en høyere gjennomsnittsalder enn allmennlegene. I dag er ca. en tredel av landets 4000 fastleger 55 år eller eldre (6). På grunn av økt ønske om fritid og fleksibilitet blant yngre allmennleger anslår man i Storbritannia at 1000 pensjonerte allmennleger må erstattes av 1500 nye allmennleger (7). Dette tilsvarer et behov for 2022 nye fastleger i Norge i løpet av de neste ti årene, kun for å erstatte eksisterende fastleger.

Professor i allmennmedisin, Steinar Hunskår, uttrykte i 2005 at Norge trengte 1000 nye allmennleger for å imøtekomme kvantitative, kvalitative og administrative oppgaver som hører til allmennlegene (8). Basert på den tradisjonelle fastlegeordningen har Legeforeningen i to ulike rapporter estimert et behov for 220 nye allmennleger årlig i perioden 2010-2020 (9) og 246 nye allmennleger årlig i perioden 2007-2016 (10). Helsedirektoratet har estimert et behov for 386 nye leger årlig i førstelinjetjenesten i årene 2009-2015 (11).

I perioden 1990-2009 ble det tilført 1400 nye legeårsverk i kommunehelsetjenesten, noe som tilsvarer 74 leger per år (12). Helsedirektoratet angir at det er kommet 62 nye legehjemler i kommunene årlig i perioden 2004-2010, noe som er betydelig mindre enn behovet skissert av Hunskår, Legeforeningen og Helsedirektoratet. Når vi samtidig vet at Helsedirektoratet ønsker å begrense arbeidsinnvandring av leger (13), begynner rekrutteringsbehovet til allmennmedisin å bli prekært.

\section{Nye utfordringer i fastlegeforskriften}

En rekke nye og utvidede oppgaver pålegges allmennlegene i den nye fastlegeforskriften: utvidet plikt til å stille opp som vikar i kommunen, utvidet møteplikt i ulike fora, plikt til å rapportere kvalitetsindikatorer fra egen praksis, plikt til å tilby time i løpet av 2-5 dager, plikt til å behandle pasienter som ikke står på egen liste, og økt deltakelse i kommunale oppgaver.

Fastlegen skal ha en «mer proaktiv tilnærming... for å oppnå målsettingene i samhandlingsreformen om mer forebygging og tidligere innsats og intervensjon, samt tettere oppfølging av pasienter med kroniske tilstander for å forebygge forverring av tilstanden og sykehusinnleggelser» (1). Dette er tidkrevende arbeid som i ytterste konsekvens medfører redusert tilgjengelighet for pasientene. Det skisseres ingen tilføring av ressurser, verken menneskelige, økonomiske eller datatekniske, for å oppfylle disse kravene. Det er derimot forskriftsfestet mulighet for økonomiske sanksjoner om oppgavene ikke blir utført adekvat (1).

\section{Mangel på allmennleger etter 2012}

Fastlegeforskriften pålegger fastlegene en rekke ekstra oppgaver. Man foreslår blant annet at fastlegen skal «kalle inn pasienter der fastlegen har opplysninger om medisinske, atferdsmessige eller sosiale risikofaktorer» og dermed «benytter seg av tjenestetilbudet $\mathrm{i}$ vesentlig mindre grad enn personens medisinske behov tilsier» (1).

Omtrent ni av ti kvinner og alle menn mellom 40-50 år i Norge har moderat eller høy risiko for hjerte- og karsykdom (14). Risikofaktorer for kreft, psykiske lidelser, kjønnssykdommer og andre tilstander kommer i tillegg. Fra 40-årsalderen er med andre ord tilnærmet alle nordmenn risikanter. Omtrent $29 \%$ av befolkningen var ikke hos fastlegen det siste året (15). Videre er $48 \%$ av befolkningen eldre enn 40 år (16). Det betyr at ca. 670000 risikanter bør innkalles til fastlegen. Hvis risikogruppen skal vurderes på gjennomsnittlig to konsultasjoner, vil dette medføre $10 \%$ økning i antall konsultasjoner. En fastlege har gjennomsnittlig 3400 konsultasjoner per år. Det vil kreve 390 nye allmennlegestillinger for å betjene denne økningen alene. Da er tidsbruk til oppsporing, innkalling, hjemme- 


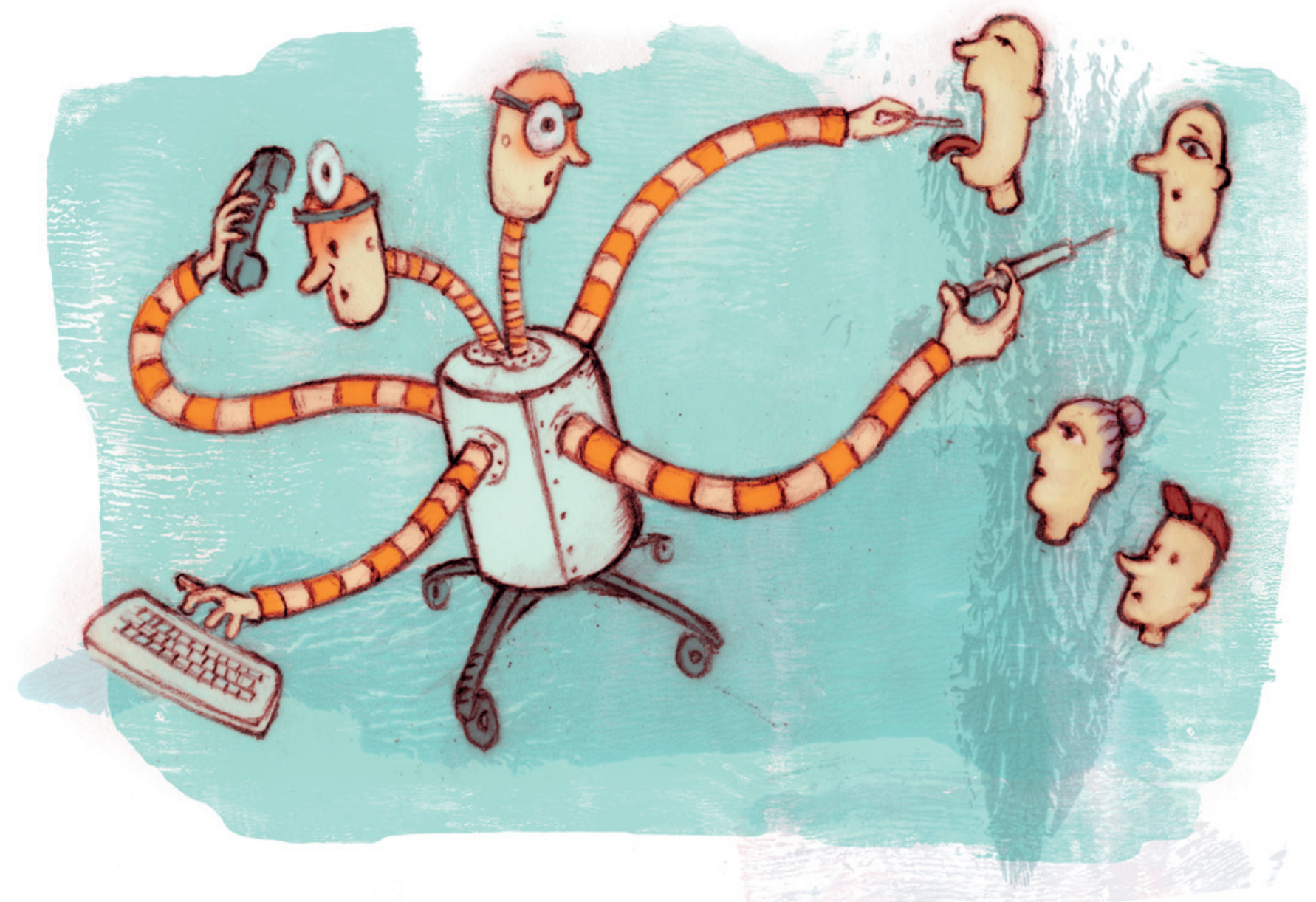

Illustrasjon Stein Løken

besøk samt øvrige oppgaver i fastlegeforskriften ikke tatt med i beregningen.

Fastlegene kan ikke løpe fortere og ønsker ikke å jobbe lengre arbeidsdager for å ivareta ovenstående arbeidsoppgaver. Skal allmennmedisinsk arbeid kjennetegnes ved kvalitet fremfor kvantitet, må den totale arbeidsmengden fordeles på flere fastleger med kortere lister.

\section{Tiltak for rekruttering}

I det nye forslaget til fastlegeforskriften står det: «...en større del av veksten i legeårsverk fremover skje i primærhelsetjenesten. Gitt dette målet er det viktig at det etableres rammebetingelser for allmennlegetjenesten og fastlegeordningen som bidrar til god rekruttering» (1). Ut over dette nevnes rekruttering til allmennmedisin i svært liten grad. Vi savner søkelys på flere viktige områder innen rekrutteringen til allmennmedisinen:

\section{Den medisinske utdanningen}

Om medisinsk utdanning står det i høringsnotatet: «Det er også viktig at legenes grunnutdanning innrettes i forhold til dette, dvs. behovet for at leger har mer kunnskap om og praksis fra primærhelsetjenesten.»

(1). Økende antall timer allmennmedisinsk undervisning, økt antall allmennmedisinske faglærere og økt antall dager med utplassering i kommunehelsetjenesten vil øke sannsynligheten for at medisinstudenter senere ønsker å jobbe som allmennlege (17). Økte ressurser til allmennmedisinsk undervisning ved de fire lærestedene i Norge kan bidra til at fastlegeforskriftens behov for øt rekruttering av allmennleger i større grad blir innfridd.

\section{Listelengde og basistilskudd}

Normtallet 1500 pasienter (300 pasienter per virkedag) i en full kurativ fastlegepraksis ble fastsatt for mer enn 15 år siden. Fastlegene er etter hvert blitt pålagt flere oppgaver. Fastlegeforskriftens intensjon er at fastlegens pasientansvar skal økes.

Normtallet må senkes hvis nye oppgaver og flere konsultasjoner per pasient skal utføres på samme tid som før. Dette var også den klare anbefalingen fra Helsedirektoratets utredning allerede i 2008 (11).

Ved å justere normtallet vil forventet pasientbelastning for nye leger bli redusert. Normtallet bør trolig reduseres ned mot 250 pasienter per virkedag. En listereduksjon fra 1500 til 1250 pasienter må kompenseres med en økning av totaløkonomien i fastlegeordningen for å oppnå en ønsket utvikling hvor fastlegen utreder og behandler mer enn i dag. Fastlegeordningens listetak på 2500 pasienter bør også nedjusteres kraftig.

\section{Oppretting av stillinger}

Oppretting av nullhjemler og tilgang på stillinger i allmennpraksis er nødvendig. Fastlønnede utdanningsstillinger i allmennpraksis som garanterer veiledning, ordnede arbeidsforhold og økonomisk sikkerhet, har vært etterlyst i mange år $(9,18)$. En ordning med 100 nye fastlønte utdanningsstillinger årlig vil koste det offentlige 200 millioner. Helse- og omsorgsdepartementet fikk i statsbudsjettet 2011 fem millioner til å opprette utdanningsstillinger i allmennpraksis, men disse midlene ble aldri disponert til konkrete tiltak i løpet av budsjettåret.

\section{Begrensede oppgaver}

Nyutdannede leger påtar seg et stort medisinsk og økonomisk ansvar når de begynner som allmennleger. Oppgavene blir større med den nye fastlegeforskriften. I alle andre spesialiteter i Norge, samt i allmennmedisinsk utdanning i Danmark og Nederland, er det et klart skille mellom en lege under opplæring og en ferdig spesialist (7). Under opplæringen har legen begrenset faglig ansvar 
og oppgaver. Dette kan redusere terskelen for å begynne i allmennpraksis.

\section{Strukturert spesialistutdanning}

Et mer strømlinjeformet og strukturert obligatorisk spesialiseringsløp er ikke vektlagt i den nye forskriften. Spesialistkomiteen har godkjent 109 spesialister årlig i perioden 2002-2009 (9). Behovet er tidligere estimert til å være 450-600 nye spesialister per år (9). Per i dag har ikke spesialistprogrammet i Norge kapasitet til å utdanne allmennlegene som trengs for å møte utfordringene og kravene i fastlegeforskriften. Ettersom kvaliteten i en fremtidig obligatorisk spesialistutdanning må beholdes, og helst økes (7), kan dette bli en flaskehals for morgendagens allmennleger.

\section{Revidert fastlegeforskrift}

Mange velger allmennpraksis på grunn av muligheten for autonomi og fleksibilitet. Vi håper at Helse- og omsorgsdepartementet revurderer fastlegeforskriftens detaljfokus på plikter og trusler om å tilbakeholde basistilskudd, da dette fremstår som skremmende og lite attraktivt for alle allmennleger, inklusive nyutdannede leger.

De undertegnende fikk, gjennom arbeid i en prosjektgruppe, tilslutning på Allmennlegeforeningens og Norsk Forening for Allmennmedisins årsmøte i 2011 til å igangsette et prøveprosjekt kalt Allmennleger $i$ spesialisering (ALIS), hvor vi skulle se nærmere på spesialistutdanningen og mulighet for økt rekruttering av fremtidige allmennleger. Nåværende forslag til ny fastlegeforskrift vil gjøre arbeidet i dette prosjektet vanskeligere da rekrutteringshindrene nå blir betydelig høyere.

\section{Andre virkemidler}

I tillegg til ovennevnte forslag finnes det en rekke andre muligheter for rekruttering; bedre trygderettigheter, samlokalisering av solopraksiser som selges, kommunal innsats for oppretting av nye «unge» legesentre, stipendordninger ved oppstart i DistriktsNorge, regulerte listepriser ved salg, oppretting av fordypningsstillinger som kombinerer forskning og allmennpraksis (19), bruk av økonomiske virkemidler for å sikre større grad av forutsigbarhet i etableringsfasen for fastleger i nye hjemler (9), bruk av normaltariff til økonomisk å kompensere for unge leger (for eksempel økt 2cd-takst hos allmennleger i spesialisering) (16), forlengelse av turnus/nybegynnerstilling i distriktene (13), overlate virksomhetsdrift til eksterne byråer m.m. Dette er momenter som kan utredes videre.

\section{Konklusjon}

De politiske signalene i fastlegeforskriften fremstår dessverre som tydelige: flere oppgaver til fastlegene, men manglende vilje til å legge ressurser i økt rekruttering til allmennmedisin. Behovet for allmennleger har vært stort, og antall allmennleger må $ø$ kes ytterligere for å kunne ivareta intensjonene i fastlegeforskriften. Dessverre frykter vi at konsekvensen av fastlegeforskriften blir redusert rekruttering til allmennmedisin.

Tiltak som bør igangsettes for å sikre rekrutteringen av leger til primærhelsetjenesten, er blant annet økte ressurser til allmennmedisinsk undervisning på universitetene, bedre tilgang på stillinger og oppretting av utdanningsstillinger. Man bør vurdere å øke basistilskudd, redusere listetak og innføre begrensede arbeidsoppgaver for allmennleger under utdanning. Spesialistutdanningsløpet må sikres og gjøre obligatorisk, og fastlegeforskriften må revideres for å sikre rekrutteringen til allmennpraksis.

\section{Stian Langeland Wesnes (f. 1978)}

er spesialist i allmennmedisin og jobber som fastlege i Bergen. Han har en ph.d.-grad som utgår fra Forskningsgruppe for allmennmedisin ved Universitetet i Bergen.

Forfatter har fylt ut ICMJE-skjemaet og oppgir følgende interessekonflikter: Både forfatteren og institusjonen har mottatt bidrag fra Helse Vest.

\section{Espen Saxhaug Kristoffersen (f. 1980)}

er under spesialisering i allmennmedisin, tidligere fastlege og kommuneoverlege i Høyanger kommune. Han er ph.d-stipendiat ved Avdeling for allmennmedisin ved Universitetet i Oslo. Forfatter har fylt ut ICMJE-skjemaet og oppgir følgende interessekonflikter: Forfatteren er styremedlem i Leger i vitenskapelige stillinger (LIS). Han har mottatt bidrag fra Avdeling for allmennmedisin, Universitetet i Oslo.

\section{Robert A. Burman (f. 1981)}

er under spesialisering i allmennmedisin. Han er fastlegevikar på Sotra, forsker ved Nasjonalt kompetansesenter for legevaktmedisin, Uni helse og ph.d.-kandidat ved Universitetet i Bergen. Videre leder han en prosjektgruppe i Legeforeningen som jobber med rekruttering til allmennmedisin

Forfatter har fylt ut ICMJE-skjemaet og oppgir følgende interessekonflikter: Forfatteren har mottatt bidrag fra Nasjonalt kompetansesenter for legevaktsmedisin.

\section{Litteratur}

1. Høringsnotat om revidert fastlegeforskrift m.m. Oslo: Helse- og omsorgsdepartementet, 2011.

2. Aasland OG, Rosta J. Fastlegenes arbeidstid 2000-08. Tidsskr Nor Legeforen 2011; 131: 1076-9

3. Hunskår S. er hjelpa nærmast! Forslag til Nasjonal handlingsplan for legevakt. Rapport $\mathrm{nr}$. 1-2009. Bergen: Nasjonalt kompetansesenter for legevaktsmedisin, 2009

4. Østbye T, Yarnall KS, Krause KM et al. Is there time for management of patients with chronic diseases in primary care? Ann Fam Med 2005; 3: 209-14.

5. Album D. Sykdommers og medisinske spesialiteters prestisje. Tidsskr Nor Laegeforen 1991; 111: 2127-33.
6. Gaardsrud $P \emptyset$. Styringsdata for fastlegeordningen, 4. kvartal 2009. Oslo: Helsedirektoratet, 2009

7. Malde K, Bjordal OA, Høvik H et al. Bør spesialistutdanningen i allmennmedisin effektiviseres? Tidsskr Nor Laegeforen 2006; 126: 1353-5.

8. Hunskår S. Eg ønskjer meg 1,000 nye fastlegar til jul. Tidsskr Nor Laegeforen 2005; 125: 3518.

9. Hoel G, Sletnes T, Kvanvik M et al. Tillit - trygghet - tilgjengelighet. Styrking av allmennmedisin og fastlegeordning frem mot år 2020. Oslo: Den norske legeforening, 2009

10. Janbu T. Policydokument: Spesialistutdanningen av leger. Oslo: Den norske legeforening, 2009

11. Utviklingsstrategi for legetjenestene i kommunene. IS-1652. Oslo: Helsedirektoratet, 2009.

12. Jacobsen E. Stadig flere leger i Norge. Tidsskr Nor Legeforen 2011; 131: 2547.

13. Nybyrjarstilling for legar - praktisk og pedagogisk oppfølging av nyutdanna legar. IS-1783. Oslo: Helsedirektoratet, 2010; 36-7.

14. Getz L, Sigurdsson JA, Hetlevik I et al. Estimating the high risk group for cardiovascular disease in the Norwegian HUNT 2 population according to the 2003 European guidelines: modelling study. BMJ 2005; 331: 551

15. Helfo. Analyserapport. Fastleger, legevakt og avtalespesialister. Aktivitetsstatistikk 2009. Oslo: Helseøkonomiforvaltningen, 2011.

16. Statistisk sentralbyrå: www.ssb.no (10.02.2012)

17. Wesnes SL, Aasland O, Baerheim A. Career choice and place of graduation among physicians in Norway. Scand J Prim Health Care 2012; 30: 35-40.

18. Thorsen O, Steinert S. Utdanningsstillinger i allmennmedisin - en nødvendig videreutvikling av fastlegeordningen. Oslo: Helsedirektoratet, 2008.

19. Wesnes SL. General practice needs to improve recruitment and income of GP researchers. Scand J Prim Health Care 2009; 27: 129-30.

Mottatt 26.1. 2012, første revisjon innsendt 9.2. 2012, godkjent 16.2. 2012. Medisinsk redaktør Are Brean. 